\title{
Study Of Effects On Micro Grid/Week Grid Stability With Implementing Droop Control For Dfig Based Turbine
}

\author{
1.N.DEEPTHI 2.V.SOWMYA SREE,Assistant Professor \\ 1,2.Department of EEE,Dr.K.V.Subba Reddy College of Engineering For Women \\ 1.n.deepthi150@gmail.com,2.sowmya.sree14@gmail.com
}

\begin{abstract}
Wind energy is going to be a significant part of electric energy generation in the very near future. However, in addition to its intermittent nature that could lead to major difficulties for power system reliability and stability, the conventional control applied to wind turbines and their generators, usually doubly-fed induction generators (DFIGs), does not allow them to participate in frequency regulation, whether short or long term. Moreover, the use of wind generators for autonomous frequency regulation is becoming an essential objective in power grids with reduced inertia and isolated microgrid operation. While droop-control is suggested by many researchers to solve these problems, detailed analysis of droop-controlled DFIG units in microgrids has not been reported. To fill-out this gap, this paper presents torque- and power-droop implementations in DFIG-based units by some simple modifications in the conventional control and then, by means of small-signal modeling and eigen-value studies, shows how both techniques in- fluence frequency stability. Sensitivity studies, with respect to the presence of turbine-and inverter-based generators in microgrids; and impacts of pitch-angle controller, wind speed variation and isolated mode operation with only wind-generators, are conducted. Timedomain simulation is utilized to verify the analytical results.

Index Terms: Doubly-fed induction generator (DFIG), droop, power sharing, small-signal modeling, stability, stand-alone operation, wind.
\end{abstract}

\section{I.INTRODUCTION}

Due to environmental, technical andfinancial issues, there is unprecedented interest in effective integration of wind based energy sources. The intermittent nature of wind could be accounted as its most challenging characteristic. To extract the maximum available power from wind with fluctuating speed, variable speed turbine is required. To cope with this requirement, a Doubly-Fed Induction Generator (DFIG) is commonly used in type-3 wind turbines as it can be controlled to maximize the extracted energy using partialscale converters with lower ratings as compared to the fullscale back-to-back converter topology used with synchronous generators.

Variable speed wind turbines fitted with a DFIG connected to the electric grid are nowadays increasingly gaining in importance due to their total automatic control of both active and reactive power output. Active and reactive DFIG control system consists of two control sub-systems: two semiconductor power converters, one on the rotor side and one on the grid side. Both converter systems employ the DFIG active and reactive power vector control. The rotor current vector is divided into two components: one controlling the magnetic flux and the other controlling the generator electromagnetic moment.

\section{DFIG WIND TURBINE CONTROL SYSTEM BASIC CONFIGURATION}

A typical DFIG wind turbine configuration consists of an induction wound generator with the stator coil connected to the three-phase grid and the rotor coil connected to the grid by means of a back-to-back semi conductor power converter. A functional block diagram of an active and reactive power wind turbine control system fitted with the DFIG and a back-to back converter connected to the electric grid is shown in Fig.1.

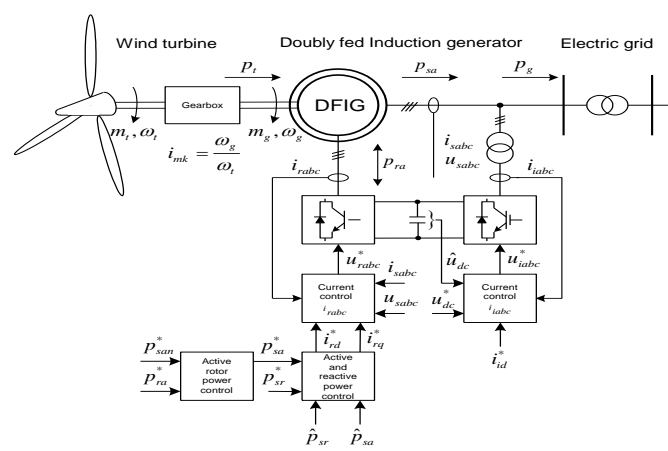

Fig.1. Wind turbine control system with DFIG

The structure of the wind turbine active and reactive power control system has been resolved by applying a known induction machine vector control based on a doubleaxis theory of electric motors. The rotor-side converter vector control system makes use of the aligned to stator magnetic flux vector coordinate system, while the grid-side converter regulation system employs the grid voltage vector.

The role of the DFIG is to convert the wind turbine mechanical power $p_{t}$ into the electric power $p_{g}$ imparted to the grid. The rotor active power can be imparted to the grid $\left(p_{r a}>0\right)$ or taken from it by the generator $\left(p_{r a}<0\right)$, or the DFIG rotor power may be equal to zero $\left(p_{r a}=0\right)$. The stator active power reference $p_{s a}^{*}$ determines the distribution of the wind turbine power $p_{t}$ to stator $p_{s a}$ and rotor active power $p_{r a}$.

By introducing a rotor active power feedback into the DFIG vector control structure an automatic generation of the required reference is obtained $p_{s a}^{*}$, thereby ensuring 
a minimum rotor active power in both stationary and dynamic generator operation modes.

In stationary operation modes the rotor power equals zero $\left(p_{r a}=0\right)$, and the electric power imparted to the grid equals the stator power $\left(p_{g}=p_{s a}\right)$.

\section{Wind Turbine Dynamic Model:}

A wind turbine mathematical model usually contains the following elements representing its basic functional components Fig.2. The wind turbine aero dynamic model, the wind turbine drive train model, the model of the DFIG induction generator fitted with a back-to-back converter in the rotor circuit, eletric grid model and the wind turbine control system model.

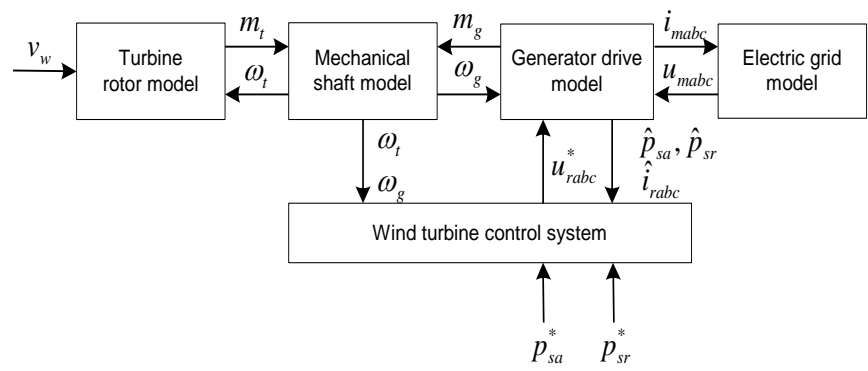

Fig.2. Block diagram of the dynamic model of a wind turbine connected to the electric grid

This paper is primarily concerned with exploring the effects of rotor power regulation within the DFIG wind turbine vector control system. Simulations have been run for the fixed electric grid and the known mean value of wind speed. The complexity of the wind turbine dynamic model has been designed in accordance with the aims of this research.

Wind turbine dynamics simulations have been run for wind step changes. The characteristic feature of the dependence of the wind turbine power upon the wind speed has been illustarted in Fig. 3 (the nominal power being 2 MW).

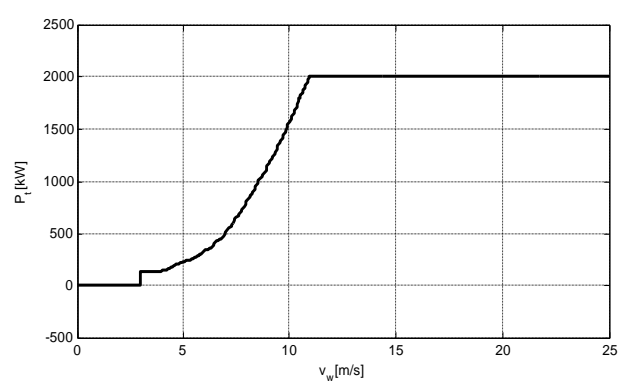

Fig.3.Static characteristic of wind turbine mechanical power $P_{t}$ as a function of mean wind speed

For a given wind speed $v_{w}$ the wind turbine power $p_{t}$ and the moment $m_{t}=p_{t} / \omega_{t}$ are obtained, the latter representing an input value into the mathematical two-mass model drive train Fig.2.

Two-mass shaft system model:

The differential equation dynamic model system coefficients are as follows: $J_{t}-$ wind turbine inertia; $J_{g}$-induction generator inertia; $D_{v t}$ - wind turbine shaft damping coefficient; $K_{v t}$-wind turbine shaft stiffness coefficient; and $i_{m k}-$ gearbox transmission ratio.

\section{DROOP IMPLEMENTATION IN DFIG}

Fig. 1 shows a DFIG-based wind power generator with interactive control for stiff-grid-connected and weak/micro grid operation modes. The DFIG system is not required to contribute to voltage regulation when the generator is connected to a stiff grid. In this mode, the DFIG is controlled to work at unity power factor. On the contrary, in islanding or weak grid mode the DFIG is forced to control its terminal voltage via the rotor side converter (RSC) whereas the grid-side converter is controlled to operate at unity power factor to minimize the converter rating. The terminal voltage controller generates the reference reactive current component.

The torque control is discussed in details in this paper. During connection to a stiff grid, a DFIG is controlled to extract the maximum available power/torque, and it does not incorporate in frequency/active power regulation. On the contrary, in the islanding/weak grid mode, it switches to droop control, which can be realized by torque-droop or power-droop. The reference torque is used to generate the reference active current component. Conventional proportional-integral (PI) controllers are used to control the RSC currents. To incorporate wind in micro- grid frequency regulation and implement droop, enough reserve power should be considered in wind power generation.
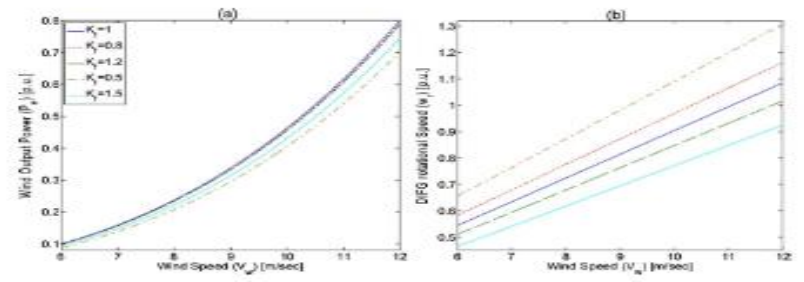

Fig. 12.Impact of the deloading factor, $\mathrm{K}_{\mathrm{f}}$, on (a) wind output power and (b) DFIG rotational speed.

The optimum torque for constant pitch-angle could be described by (1) in which constant and represents the DFIG rotational speed

$$
T_{e, 0 p t}=K_{o p t} \omega_{r}^{2}
$$

By multiplying the right term of (1) with a deloading factor, $\mathrm{K}_{\mathrm{f}}$, the operating point will deviate from the maximum extraction point. The impact of on the wind generation output and rotational speed is shown in Fig. 2. Although this deviation could be accounted as a loss, it allows the droop implementation

$$
T_{c, \text { deloaded }}=K_{f} K_{\text {opt }} \omega_{r}^{2} \text {. }
$$

\section{A. Torque-Droop}

Similar to a conventional power/frequency droop, shown in (3), (1) could be modified as given by (4), where is angular frequency of microgrid, whereas is the microgrid preset frequency and is the droop factor. The 
first term in (4) plays the role of nominal power, in (3), however (4) yields a torque-droop which varies with the wind speed:

$$
\begin{gathered}
P=P_{n}-\frac{\left(\omega_{m}^{*}-\omega_{m}\right)}{K_{p}} \\
T_{e, T r D r-\text { ref }}=K_{f} K_{\mathrm{opt}} \omega_{r}^{2}-m_{p}\left(\omega_{m}^{*}-\omega_{m}\right) .
\end{gathered}
$$

To study the impact of this modification on wind power generation, modeling the wind power generation, including wind turbine, DFIG and the back-to-back converter, is needed. However, in case of proper tuning of the controller parameters, the dynamics of a wind generator could be described by the rotating mass behavior given in (5) and other parts which are much faster could be ignored. With the help of the participation factor analysis, it could be shown that the dominant poles of wind power generator transfer function are dominated by (5). In (5), and DFIG inertia constant and electrical active power output, respectively. is the mechanical input of the turbine, and it is given by (6) where is air density; is the power coefficient of the wind turbine is tip ratio is effective area covered by the turbine blades is the pitch-angle; and is wind speed:

$$
\begin{aligned}
P_{m}-P_{e} & =2 H_{\mathrm{DFIG}} \omega_{r} d \omega_{r} / d t \\
P_{m} & =0.5 \rho C_{P}(\lambda, \beta) A_{r} v_{w}^{3} .
\end{aligned}
$$

For further analysis, small-signal modeling is utilized. Thus, (5) and (6) could be rewritten as (7) and (8), respectively. It should be mentioned that unlike conventional operation at maximum power point, here because of deviation from maximum power point:

$$
\begin{aligned}
\Delta P_{m}-\Delta P_{c} & =2 H_{\mathrm{DFIG}} \omega_{r 0} \frac{d \Delta \omega_{r}}{d t} \\
\Delta P_{m} & =A_{1} \cdot \Delta \beta+A_{2} \cdot \Delta \omega_{r}+A_{3} \cdot \Delta v_{w}
\end{aligned}
$$

where

$$
\begin{aligned}
& A_{1}=\frac{\partial \Delta P_{m}}{\partial \Delta \beta}=0.5 \rho A_{r} V_{w 0}^{3} \frac{\partial \Delta C_{P}}{\partial \Delta \beta} \\
& A_{2}=\frac{\partial \Delta P_{m}}{\partial \Delta \omega_{r}}=0.5 \rho A_{r} V_{w 0}^{3} \frac{\partial \Delta C_{P}}{\partial \Delta \lambda} \frac{\partial \Delta \lambda}{\partial \Delta \omega_{r}} \\
& A_{3}=\frac{\partial \Delta P_{m}}{\partial \Delta v_{w}}=0.5 \rho A_{r}\left(3 C_{P} V_{w 0}^{2}+V_{w 0}^{3} \frac{\partial \Delta C_{P}}{\partial \Delta \lambda}, \frac{\partial \Delta \lambda}{\partial \Delta v_{w}}\right) .
\end{aligned}
$$

After mathematical manipulation, the output power dynamics, with torque-droop, can be given by (12), shown at the bottom of the page. It is worthy to mention that in this step, the pitch-angle is considered constantly zero and consequently it is omitted from the small-signal dynamic model. The impact of the pitch-angle controller will be discussed in Section III.

\section{B. Power-Droop}

The term in the denominator of (12) indicates a dependency on the initial operating (equilibrium) point frequency which is not desirable and may make the design more complex. In fact, this term could be removed by reference torque modefication as follows:

$$
\begin{aligned}
& \Delta P_{e, T r D r}(s)
\end{aligned}
$$

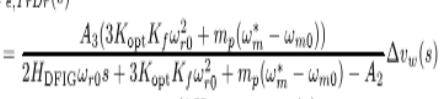

$$
\begin{aligned}
& +\frac{-m_{p} \omega_{r 0}\left(2 H_{D F F G} \omega_{r 0} s-A_{2}\right)}{2 H_{D F G G} \omega_{r 0} s+3 K_{\text {op }} K_{\rho} \omega_{r 0}^{2}+m_{p}\left(\omega_{m}^{*}-\omega_{m 0}\right)-A_{2}} \Delta \omega_{m} \cdot(s)
\end{aligned}
$$

$$
T_{e, P o D r-r e f}=K_{o p t} \omega_{r}^{2}-m_{p}\left(\omega_{m}^{*}-\omega_{m}\right) / \omega_{r} .
$$

Equation (13) to enhance the short-term, not steadystate, frequency dynamics, while a gas turbine generator was responsible for frequency restoration and wind generator was not deloaded. With this modification, the droop is implemented in power instead of torque and the output of wind power generation, with power-droop, will be given by

$$
\begin{gathered}
\Delta P_{e, P o D r}(s)=\frac{3 A_{3} K_{\mathrm{opt}} K_{f} \omega_{r o}^{2}}{2 H_{\mathrm{DFIG}} \omega_{r 0} s+3 K_{\mathrm{opt}} K_{f} \omega_{r 0}^{2}-A_{2}} \Delta v_{w}(s) \\
+\frac{-m_{p}\left(2 H_{\mathrm{DFIG}} \omega_{r 0} s-A_{2}\right)}{2 H_{\mathrm{DFIG}} \omega_{r 0} s+3 K_{\mathrm{opt}} K_{f} \omega_{r \mathrm{o}}^{2}-A_{2}} \Delta \omega_{m}(s)
\end{gathered}
$$

Obviously, the undesired term is omitted; however, the steady- state and dynamic behavior will also be altered.

\section{Steady-State Analysis:}

Using (12) and (14), the wind droop dynamics could be discussed more precisely and in details. The steady-state response of wind power generation to change in frequency regulation, with torque-droop and power-droop, could be described by (15) and (16), respec-tively. Obviously, the steady-state response in (15) it is not merely determined by the droop factor in (4). In other words, the effective droop factor is a function of initial (equilibrium point) wind speed (and equivalently (equilibrium point) initial DFIG rotational speed), (equilibrium point) initial microgrid frequency and . Therefore, the effective droop factors and are introduced in (17)-(18), fortorque- and power-droop methods, respectively. Equations (17) and (18) indicate that several unconventional factors impact power/frequency regulation and may result in deviation of the effective droop factor from its expected constant value, :

$$
\begin{aligned}
\Delta P_{T r D r, s s} & =\frac{m_{p} \omega_{r 0} A_{2}}{3 K_{\mathrm{opt}} K_{f} \omega_{\mathrm{r} 0}^{2}+m_{p}\left(\omega_{m}^{*}-\omega_{m 0}\right)-A_{2}} \Delta \omega_{m} \\
\Delta P_{P o D r, s s} & =\frac{m_{p} A_{2}}{3 K_{\mathrm{opt}} K_{f} \omega_{\mathrm{r} 0}^{2}-A_{2}} \Delta \omega_{m} \\
m_{\text {eff }, T r D r} & =m_{p} \cdot K_{\text {eff }, T r D r} \\
& =m_{p} \cdot-\frac{\omega_{r 0} A_{2}}{3 K_{\mathrm{opt}} K_{f} \omega_{r 0}^{2}+m_{p}\left(\omega_{m}^{*}-\omega_{m 0}\right)-A_{2}} \\
m_{\mathrm{eff}, P o D r} & =m_{p} \cdot K_{\mathrm{eff}, P_{o} D r} \\
& =m_{p}-\frac{A_{2}}{3 K_{\mathrm{opt}} K_{f} \omega_{r 0}^{2}-A_{2}} .
\end{aligned}
$$

Fig. 3 shows the effective droop factor versus wind speed considering different deloading factors. This figure reveals why the lower than unity should be chosen even if a larger than unity one also results in deviation from maximum power tracking point. In fact, a higher than unity leads to a negative effective droop factor which works as a positive feedback for power/frequency regulation and is highly undesirable. Previously advised to avoid higher than one , the reason behind this criterion is neither given nor quantified by analysis. 


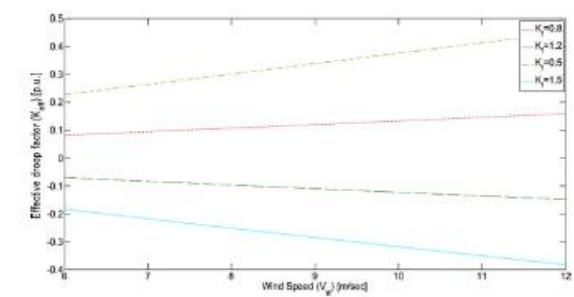

Fig. 3. Effective droop factor, $K_{\epsilon \ell, T r D r}$, versus wind speed, $V_{w}$
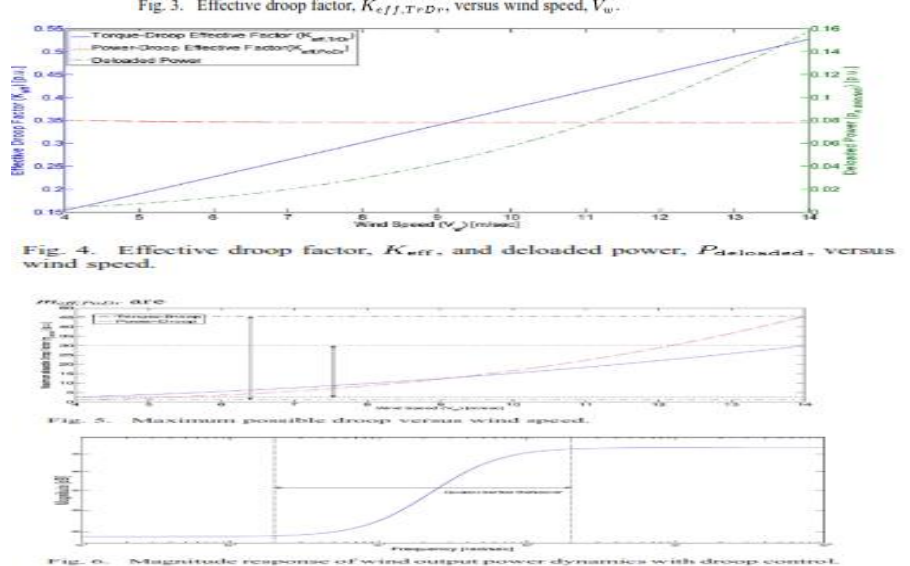

the other hand, conservatively choosing a small droop factor to ensure stability leads to inefficient use of the deloaded power.

Therefore, while power-droop is preferred because of its independency of system frequency, the torque-droop shows better performance with respect to the deloading effect. More importantly, the dependency of torque-droop on system initial frequency makes the analyses more complicated. However, it does not result in instability. On the contrary, a constant effective power-droop factor could make the system unstable:

$$
\begin{aligned}
& m_{p, \max }=\frac{\Delta P_{\max }}{\Delta \omega_{m, \max }} \\
& m_{p, \max }=\frac{\Delta P_{\text {deloaded }}}{K_{\text {eff }} \Delta \omega_{m, \max }} .
\end{aligned}
$$

In other words, these analyses show how wind droop is different from conventional dispatchable inverter-based droop. While the concepts of de laoding (over and under speeding) and torque-droop could not be discussed in such well known studies, ignoring these facts for a wind droop could lead to highly misleading results.

\section{Semi-Inertial Behavior:}

The term in the numerator of (12) and term in the numerator of (14) resemble inertial response. As shown, in the medium frequency range it emulates a physical inertia but it is not a wide or even constant range as it depends on wind speed. On the contrary, the major impact of a real inertia is in the high frequency range, equivalently right after a power disturbance. Although this term is not going to act exactly as inertia, it seems to be useful in overall system stability, which will be discussed in more details in the next sections. This resem blance could also explain why in references, the wind-droop method is utilized merely for short term power/frequency regulation and how it influences the system transient stability. On the other hand, the droop method is generally recognized for its positive impact in steady-state conditions.

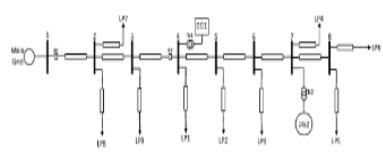

Fig. 7. System under-study.

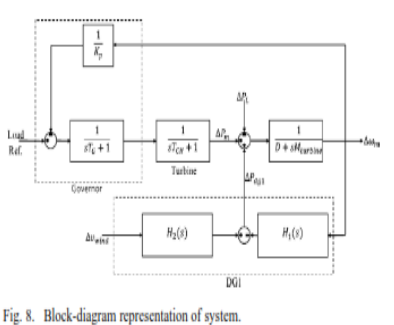

\section{STABILITY ANALYSIS OF DFIG}

For further investigations, a typical medium voltage rural distribution system, a real system in Ontario, Canada, shown in Fig. 7, is adopted. The segment after the circuit breaker B2 has the ability to work in islanded mode and constitutes the micro- grid. The overall load of this section is 3.77 MW/1.24 MVAr. It contains two DG units. DG1 is a variable speed wind turbine connected to a $2.5 \mathrm{MVA}$ DFIG with its rotor interfaced by back-to-back converters. DG2 is a 2.5 MVA synchronous generator with droop and excitation control systems. System parameters are given in the Appendix. The stability analysis could be extended to larger microgrid or weak grids which suffer from reduced inertia.

\section{Impacts on Stability:}

The wind generation model presented in the last section can be combined with the gas turbine generator model to form the overall frequency dynamics model of the system ,where and can be obtained depending on the droop-method used. This model can be effectively used to show how wind droop could impact the frequency stability.

Fig. 9 shows the root locus of system dominant poles when, the wind torque-droop factor, is increased.
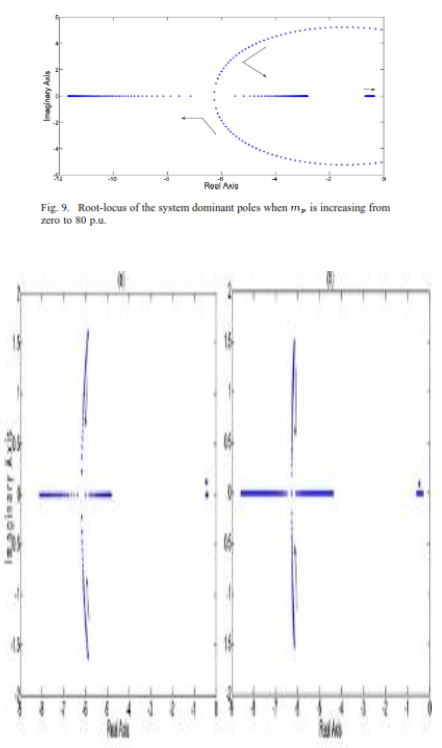

Fig: 10. Root-bous of the system doninand ples at $\mathrm{W}_{w}=12 \mathrm{~ms}$ and $\mathrm{m}_{\mathrm{p}}=$ 40 (a) K/ is decreasing from 1 to 0.4 p.u and (b) initial (equilitrium poirt) frequency is increasing fron $59.41060 .6 \mathrm{~Hz}$ 

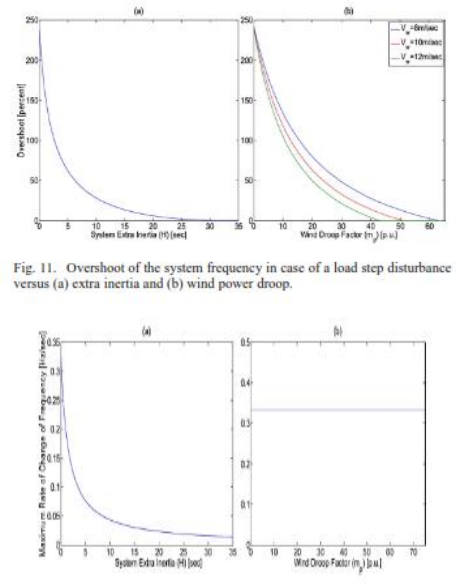

Fige. 12. Maximum ROCOF of the system frequency in case of a load stef distublance versus (a) extra inertia and (b) wind power droop.

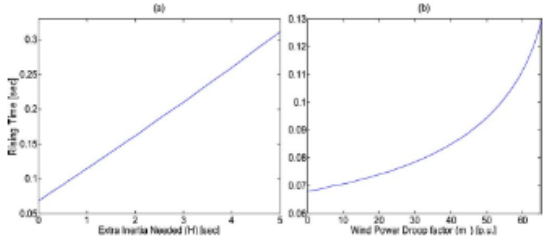

Fig. 13. Rise-time of the system frequency in case of a load step disturbanes

(a) with extra inertia and (b) with wind power droop.

Interactions and Coordination With Other Units:

Although it seems that the wind-droop (both torque- and power-droop methods) solely has positive impact on system performance, its interactions with other system units, e.g., turbine and inverter-based DG units could be a concern. Further, interactions with the pitch-angle controller should be investigated.
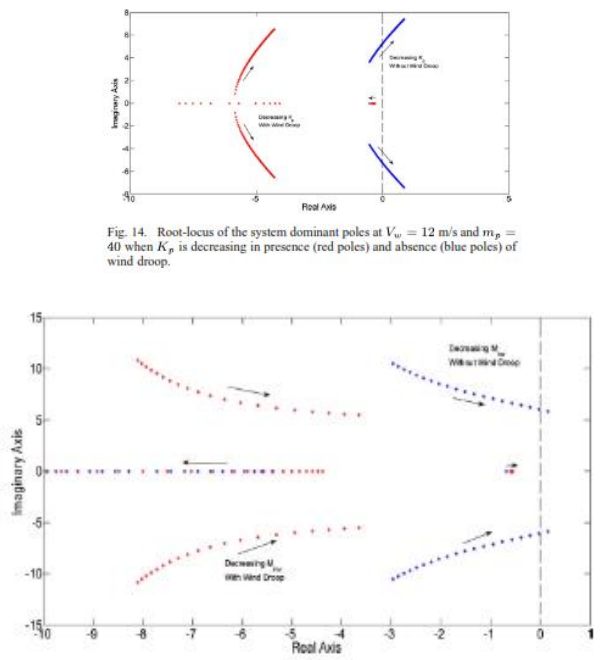

Fig. 15. Root-locus of the system dominant poles at $V_{w}=12 \mathrm{~m} / \mathrm{s}$ and $m_{y}=$ 40 while $m_{i n e}$ is decreasing in presence (red poles) and absence (blue poles) of wind droop.

1) Gas Turbine:

Gas turbine as the other source and only dispatchable source in this case-study plays important role in both dynamic and static system behaviors. Its governor, which is responsible for frequency regulation, is also equipped with droop, similar to (2).

\section{2) Inverter:}

Nowadays, many DG units are inverter-inter- faced and this may lead to interactions between wind-droop and inverter-based droop units. The inverter model should be added. An inverter could be represented by a power controller block in frequency dynamics studies. Thus, a transfer function, based on (21), should be fed back to the input of the turbine inertia block. In (21), and are the power and droop gain of the of the inverter based DG unit, respectively and is the time-constant of the equivalent low-pass filter model of the inverter dy- namics (mainly due to the low-pass filter applied to extract the average power, and inner control loop dynamics):

$$
\Delta P_{\mathrm{inv}}=-\frac{m_{\mathrm{inv}}}{\tau_{\mathrm{inv}} s+1} \Delta \omega_{m}
$$

Fig. 15 depicts the impact of lowering the inverter droop factor, , on the system stability. The inverter droop gain may result in instability (Hopf bifurcation) as shown by the blue poles in Fig. 15 . Fortunately, the presence of wind-droop could solve this problem by adding more damping to the dominant modes as shown by the red poles in Fig. 15. The presence of wind-droop allows the system operator to change the inverter parameters in a wider range to meet the economic operation constraints. It is worthy to mention that wind-droop could also eliminate stability problems associated with inappropriate tuning of the inverter average power filter.

\section{3) Pitch-Angle Controller:}

Up till now, the pitch angle controller is not considered however, in reality a wind generation unit might operate in this regime for a considerable time especially when wind generation output is at its maximum. The pitchangle controller is used to limit the wind power output and its rotational speed. In conventional wind generation, the reference torque value, previously described by (1), changes into a constant torque.
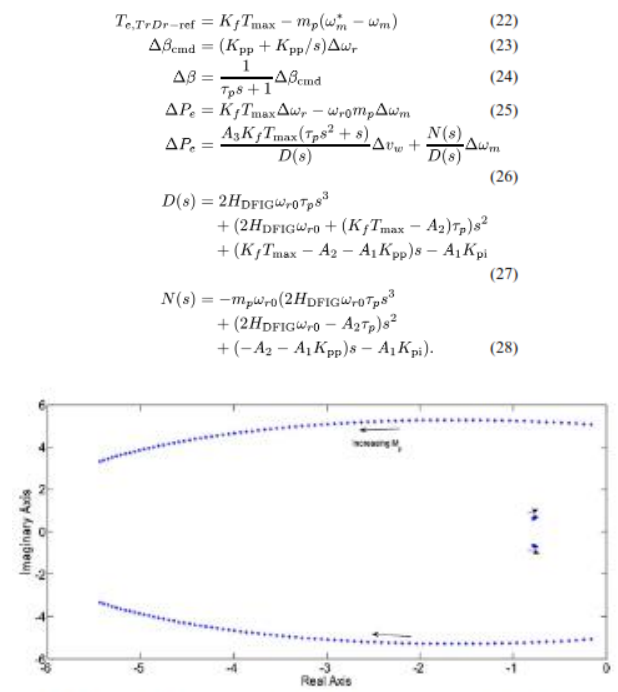

Fig. 16. Root-locus of the system dominant poles when $m_{p}$ is increasing fron zero to 80 p.u. and pitch-angle controller is activated.

After mathematical manipulation, the wind power 
output could be derived as given in (26) which should be used in Fig. 8. This new model reveals how wind-droop acts in the presence of pitch-angle control dynamics. Dominant eigenvalues are shown in Fig. 16 which shows that winddroop still influences positively and indeed the pitch-angle controller does not impact the wind-droop dynamics significantly. This is due to the fact that the pitch-angle controller is much slower than the RSC controller. Furthermore, it shows that the major disadvantage of deloading, i.e., high rotational speed could be solved simply by employing a conventional pitch-angle controller.

\section{SIMULATION RESULTS}

Time-domain simulation, using Matlab/Simulink, is usedto verify the analytical results discussed in the previous section using the system understudy shown in Fig. 7. Two different scenarios are investigated. The first deals with the case of both wind and gas turbine generators, whereas the second uses only wind power generation. Each scenario consists of different cases. DG2 is modeled based on details discussed in [22]. The droop and excitation system models are also included. Typical distribution system lines, with low X/R ratio , are modeled as lumped R-L and the loads as parallel R-L elements. System parameters are given in Appendix.

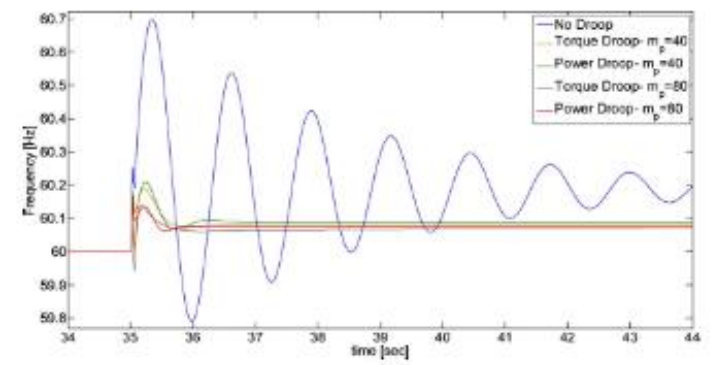

Fig. 17. Frequency response when wind speed is $13 \mathrm{~m} / \mathrm{s}$ and $K_{f}=0.5$.

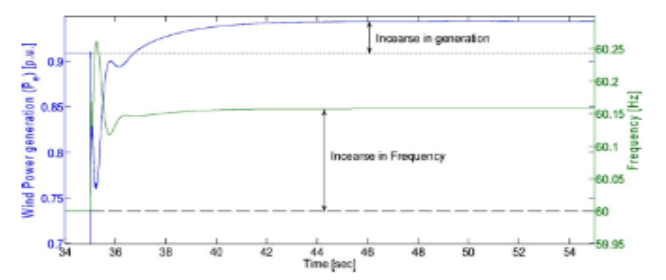

Fig. 18. Frequency and wind power generation responses when wind speed is
constant at $13 \mathrm{~m} / \mathrm{s}$ and $K_{f}=1.5, m_{p}=40$.

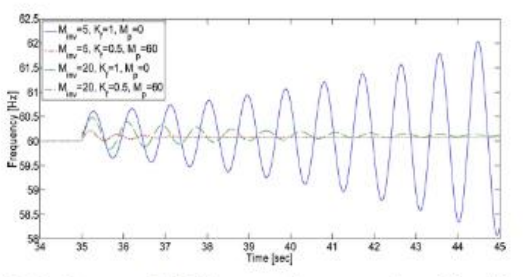

Fig. 19. Frequency and wind Power generation responses when wind speed is
constant at $13 \mathrm{~m} / \mathrm{s}$ and $K_{f}=1.5, m_{y}=40$.

\section{A. Gas Turbine Plus Wind:}

Firstly, to reduce the complexity, constant wind speed is considered. Later, to present a more realistic case, a real wind speed pattern is used.

1) Constant Wind Speed:

a) Under-Rated Speed: An intentional islanding occurs at $s$. The system frequency is shown in Fig. 17 without winddroop and with wind-droop implemented as power- or torque-droop at different droop gains. As depicted, not only the final frequency but also the transient behaviors are improved as predicted by the analytical findings reported in the previous sec-tions and despite the low X/R ratio. It also confirms the results of Fig. 9; i.e., larger results in better dynamic behavior.

b) Under-Speeding: It was previously shown that choosing higher than one may result in negative effec- tive droop. Fig. 18 shows the wind generator output when. While the system has excessive generation sim-ilar to the pervious case, and frequency has increased after islanding, the wind power output, despite the philosophy of implementing droop, has also increased. Indeed, wind-droop with under-speeding dictates higher fluctuations to dispatchable sources outputs and it is not capable of feeding a microgrid alone.

c) Inverter Interaction: In this scenario, an inverter-based DG unit is added to bus 8 in the system and turbine droop factor has also been modified. The inverter is modeled based on [24]. Fig. 19 shows the system frequency in several scenarios. While decreasing the inverter droop factor has worsen both the steady- state and the dynamic behaviors, the presence of wind-droop improves the system stability. It can even stabilize the unstable system as predicated by the analytical results.

2) Variable Wind Speed: In this scenario, a real wind speed pattern, which is derived from real measured wind speed [25] data, is used, and it is shown in Fig. 20.

a) Wind Droop: To prevent the interference between the intentional islanding disturbance and impacts of variable wind speed, islanding has taken place long enough before $\mathrm{t}=30$.

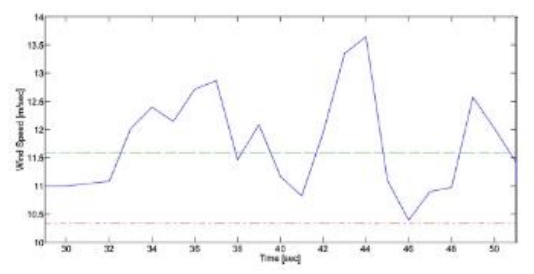
Fig. 20. Real wind speed pattern (blue solid line). The minimum wind speed
needed for stand-alone wind operation (green and red dashed lines) will be it-

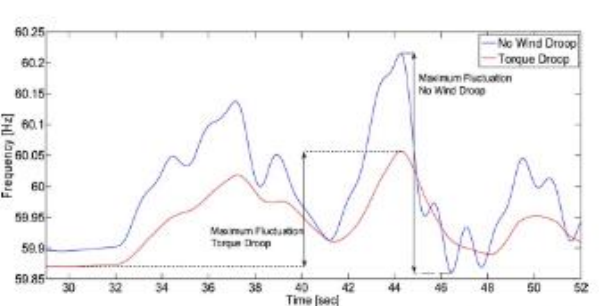

Fig. 21. Frequency responses when wind speed is varying. Islanding had taken place long enough before wind speed starts to change.

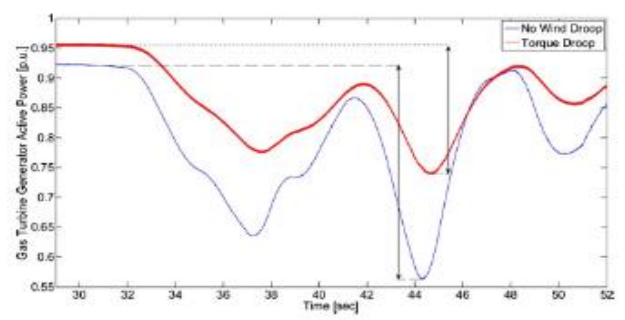

Fig. 22. Gas turbine generator output power response when wind speed is varying. Islanding had taken place long enough before wind speed starts to change. 

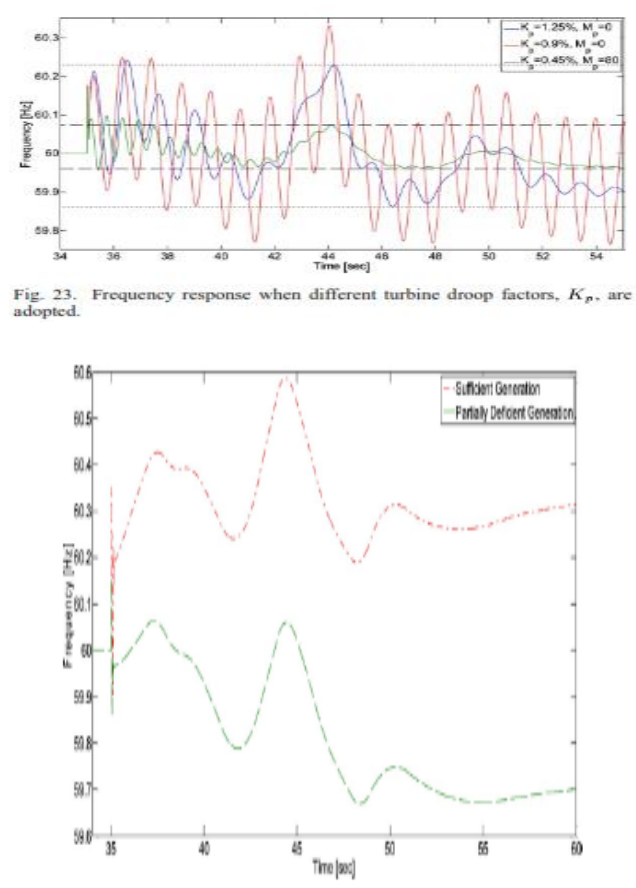

Fig. 24. Frequency response for stand-alone wind power generation.

\section{B. Stand-Alone Wind:}

With appropriate energy management, sensitive loads can be fed from a wind generation under the outage of dispatchable resources or other microgrid contingencies. In this scenario, it is assumed that wind generation is enough for essential loads in a microgrid and merely studies shortterm frequency stability issues (not long-term power dispatching). It should be noted that with the excessively increasing penetration levels of wind power in power systems and advances in forecasting and energy management methods, this scenario is very likely to happen in near-term microgrids.

1) Single Wind Generation Unit: In this part, the gas turbine generator unit is removed and load 2 is changed for genera- tion-load matching. Green and red-dashed lines in Fig. 20 show system loading levels regarding wind speed; indeed, they specify the minimum wind speed required to feed the loads. It should be noted that in steady-state in both cases, available wind power is sufficient. However, in some cases, e.g., for the green line, some short-term deficiencies occur. Fig. 24 depicts the frequency in both cases, which are stable. This experiment reveals that short-term deficiency in available wind power could be afforded due the kinetic energy provided by the rotating mass. Fig. 25 illustrates the active and reactive power output of wind generator in both cases.

2) Multiple Wind-Power Generators: In this scenario, load 2 is restored and another wind power generator is added to bus 7 , the same place of the gas turbine unit. Similar to the pervious part, firstly, constant wind speed is utilized; then a typical wind speed profile is employed.
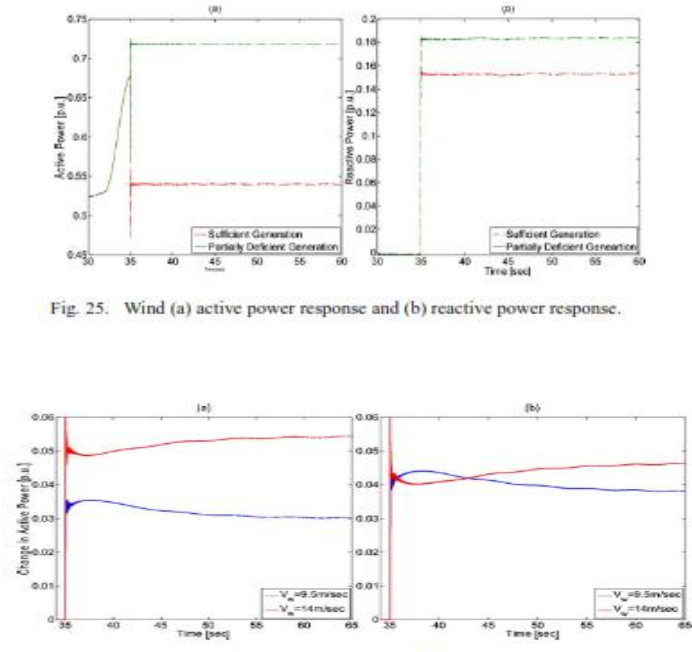

Fig. 20. Changes in active power output of stand-alone wind power generations
with different wind speeds, $V w$, when droop is implemented in (a) torque and
(b) power.

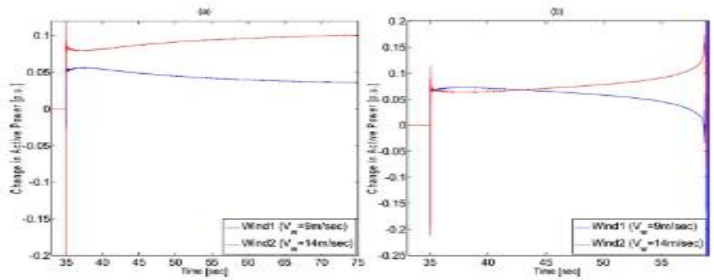

Fig 27 . Changes in active power output of stand-alone wind power generations
with different wind speeds, $V w$, when droop is implemented in (a) torque and with different wind speeds, $V_{w}$, when droop is implemented in (a) torque and

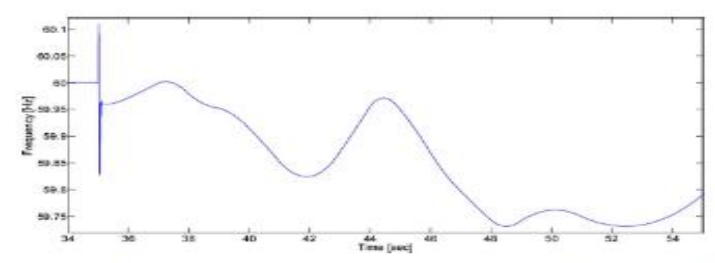

Fig. 28 . Frequency versus time when two stand-alone wind generators with
identical wind speeds regulating the microgrid frequency.

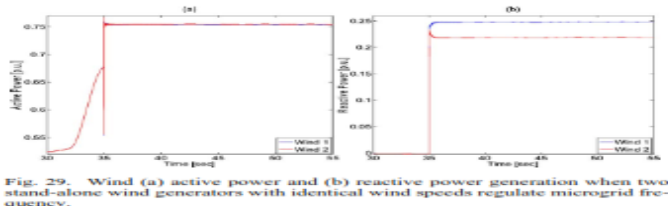

a) Constant Wind Speed: One of the generators works at $14 \mathrm{~m} / \mathrm{s}$ whereas the other operates at $\mathrm{m} / \mathrm{s}$ and the droop factor is the same for both. Fig. 26(a) shows the output power re- sponses of both generators when torque-droop is implemented, whereas Fig. 26(b) shows the same when power-droop is used. With torque-droop, generator with higher wind speed has higher share in power regulation. In contrast, power-droop yields al- most equal power sharing. These differences could be illustrated by Fig. 4, where the effective droop factor is discussed. As ex-pected, in torquedroop, the wind generator with higher wind speed has a higher effective droop factor.

In the previous sections, it was reported that the almost constant effective droop factor of power-droop, while the deloaded power is not constant, could result in instability. The case of Fig. 27 confirms this argument which is similar to the case of Fig. 26 but now the lower wind speed is decreased from 9.5 to $9 \mathrm{~m} / \mathrm{s}$. Again in power-droop method, 
the DG unit with lower wind speed and less available power is forced to provide almost the same power as the other unit with higher wind speed so the incapability of this DG unit leads to instability and consequently microgrid failure. It is worthy to mention that exactly the same scenario but with torque-droop remains stable [Fig. 27(a)].

\section{C) Variable Wind Speed:}

(1) Similar Wind Speed Patterns In this part, both wind power generators experience the same wind speed pattern shown in Fig. 20. Figs. 28 and 29 show the frequency regulation and the power sharing responses, respec- tively. Since both DG units have same parameters, they share the active power equally.

(2) Different Wind Speed PatternsA different wind speed pattern, derived from [25] and shown in Fig. 30, is used for one DG unit whereas the other unit still works with the previous wind speed pattern shown in Fig. 20 (shown by blue solid line in Fig. 30).

Fig. 31 illustrates the power sharing performance. Becauseof variable wind speed and dependency of the effective droop factor, a unit with higher wind speed generates more power which seems reasonably beneficial. Fig. 32 reveals the micro- grid frequency response in this case.
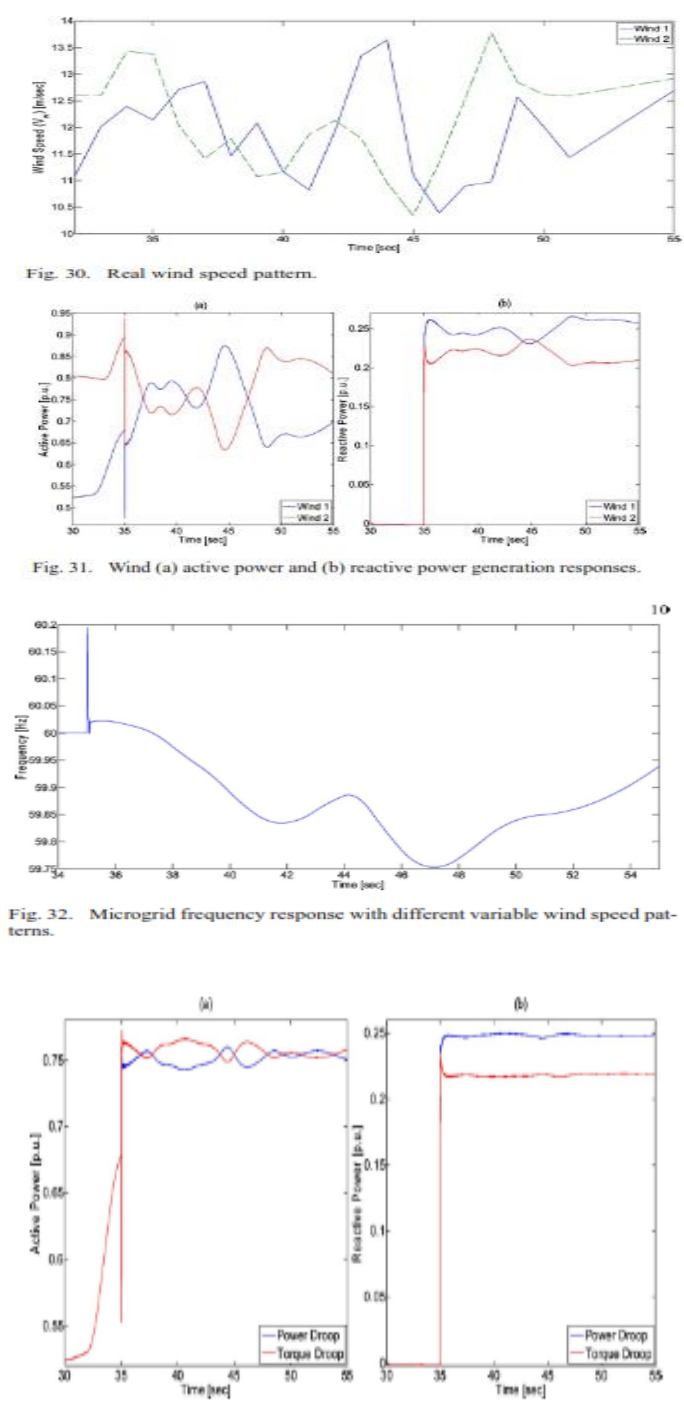

Fig. 33. Wind (a) active power and (b) reactive power generation responses.

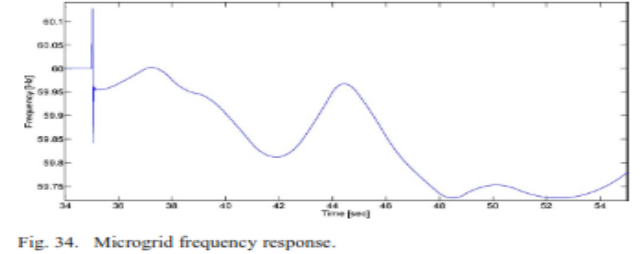

(3) Compatibility Between Torque- and Power-Droops A question may arise about the compatibility between the power and torque-droop as two possible droop methods. With wind speed patterns are exactly the same, one of DG units is equipped with torque-droop whereas the other unit adopts power-droop. Comparing Fig. 33, showing the power sharing in this case, with Fig. 29, reveals that despite the same parameters, power sharing is not completely equal due to the impact of the effective droop factor as explained before. The micro-grid frequency response is also shown in Fig. 34.

Simulations for wind step changes $v_{w}=9[\mathrm{~m} / \mathrm{s}]$ at the moment $t=6[s]$ and $v_{w}=14[\mathrm{~m} / \mathrm{s}]$ at the moment $t=50[s]$ have been run within the research as presented in this paper (Fig.5). Figures 6., 7. and 8. illustrate time responses of the generator rotor rotational speed $\omega_{g}$.

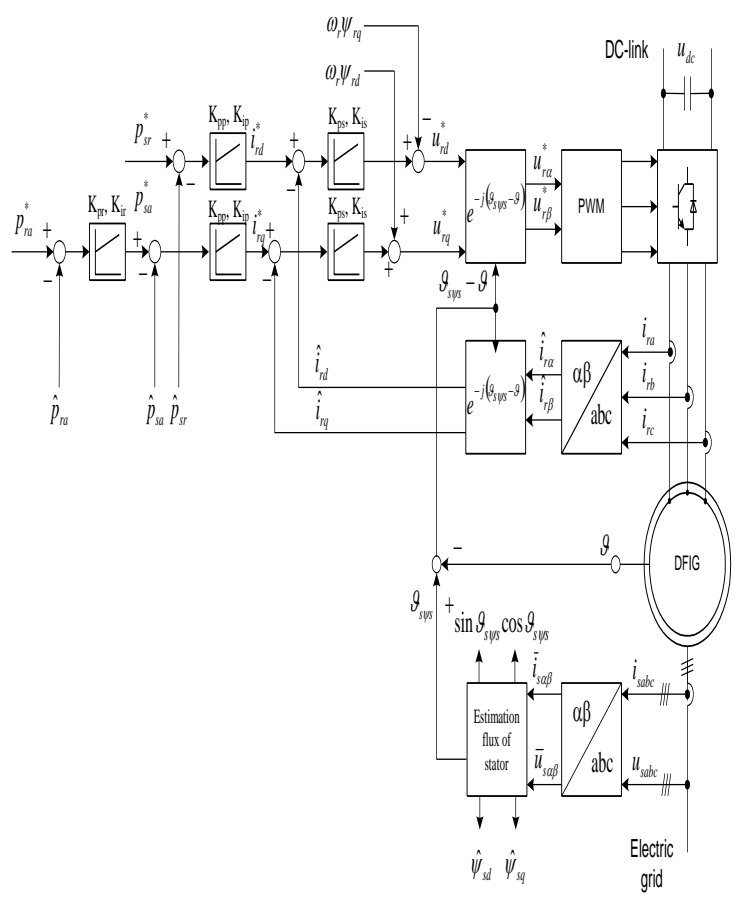

Fig. 4. Active and reactive power vector control system of DFIG with rotor power feedback control

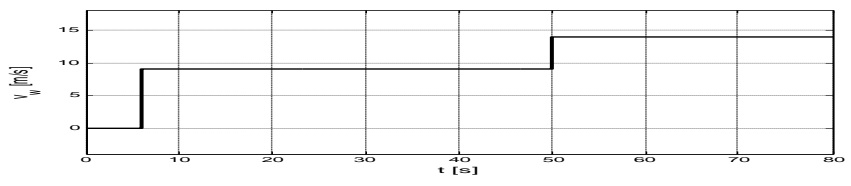

Fig.5. Wind speed time dependence 

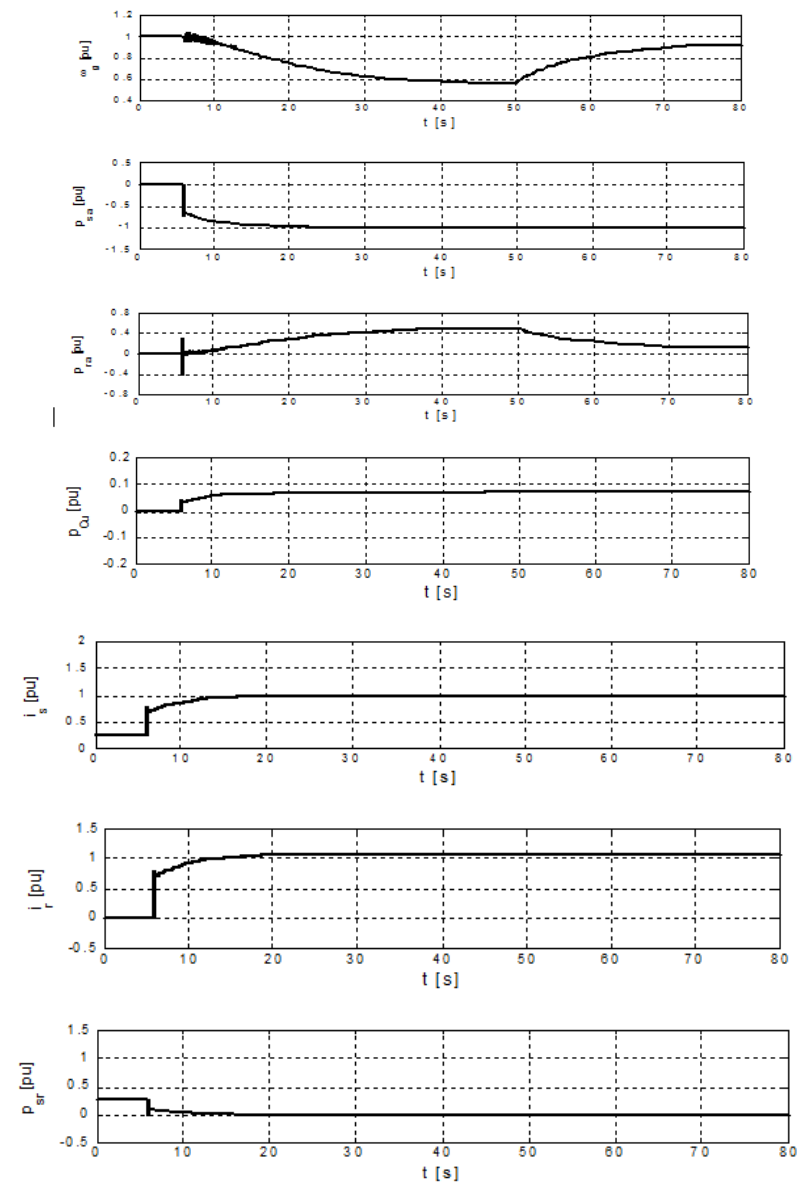

Fig.6. Time responses without the rotor active power regulation

Current vector value $i_{s}$, rotor current vector value $i_{r}$, as well as the DFIG stator reactive power $p_{s r}$. Time responses simulations have been run with respect to the stator active power reference $p_{s a}^{*}=1.0[p u]$, stator reactive power reference $p_{s r}^{*}=0.0[p u]$ and the rotor active power reference $p_{r a}^{*}=0.0[p u]$. The calculations have been done by means of the parameters pertaining to the wind turbine and induction generator of $2 \mathrm{MW}$ power as qouted.

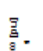
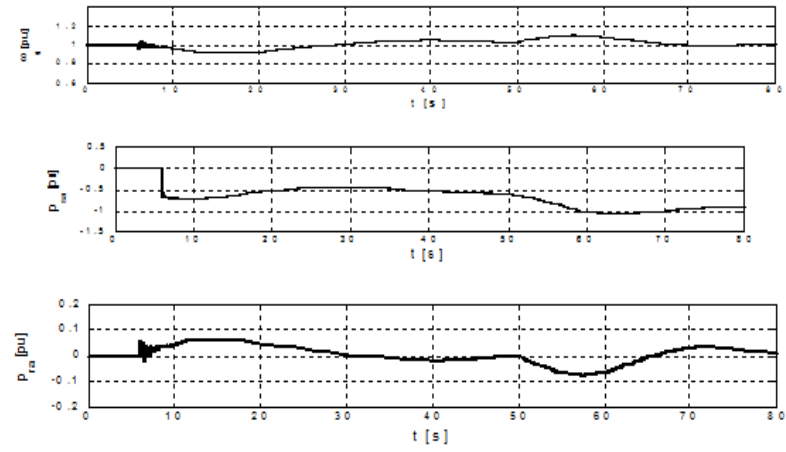
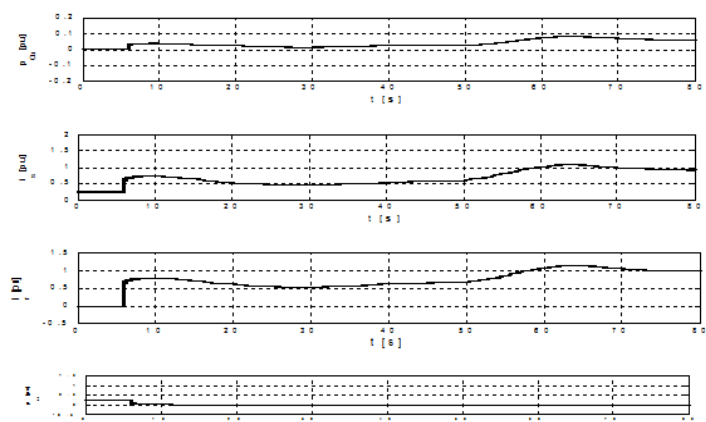

Fig.7. Time responses with the rotor active power regulation; $K_{p r}=2.0, K_{i r}=0.002, p_{r a}^{*}=0.0[p u]$.

Simulation of the vector control time responses without the rotor active power regulation has been shown in Fig. 6, whereas Figures 7. and 8. illustrate the time responses with the rotor active power regulation. The rotor active power regulation parameters as shown in Fig.7. are equal to the stator power regulation in the DFIG cascade regulation mode ( $K_{p r}=2, K_{i r}=0.002$ ). All the physical values presented in this figure display a pronounced transitional phenomenon.

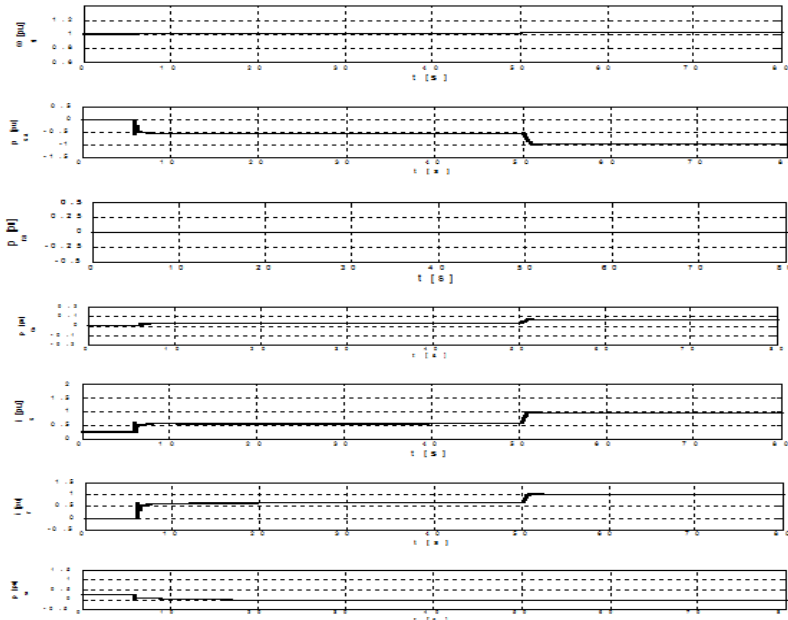

Fig.8. Time responses with the rotor active power regulation;

$$
K_{p r}=100.0, K_{i r}=0.05, p_{r a}^{*}=0.0[p u] \text {. }
$$

Considerably better indicators of regulation quality are obtained, as shown in Fig.8. Transitional phenomena of electric values are considerably shorter, thereby rendering the entire DFIG wind turbine system more adjustable to sudden wind step changes. The DFIG vector control system fitted with rotor active power regulation follows the power obtained from the wind turbine regardless of the given stator active power reference.

Figures 7. And 8. Illustrate time responses of rotation speed and active power, currents and losses in both stator and rotor when the rotor active power reference equals zero $\left(p_{r a}^{*}=0.0[p u]\right)$. By this reference a synchronous operation mode of the asynchronous generator is ensured.

Then the rotor active power in the wind turbine stationary operation modes also equals zero. By means of connecting the rotor active power external feedback with the rotor active power reference equaling zero 
( $p_{r a}^{*}=0.0[p u]$ ), the desired dynamic characteristics of the DFIG wind turbine system can be realized, which applies to all wind speed changes providing the wind turbine power above the nominal $\left(p_{t}>2 M W\right)$.

It is known that an optimum wind turbine operation requires the wind turbine rotation speed to be reduced at lower wind speeds, as well as all wind speed changes accounting for wind power turbine below the nominal value $\left(p_{t}<2[M W]\right)$.

The DFIG vector control system fitted with active rotor power external feedback enables the wind turbine speed rotation to be controlled by means of controlling the reference $p_{r a}^{*}$

Stationary characteristics of rotation speed $\omega_{g}$, active power imparted to the grid $p_{g a}$, losses in copper $p_{C u}$, respective stator $i_{s}$ and rotor currents $i_{r}$, as well as stator and rotor active powers $p_{s a}$ and $p_{r a}$ respectively, depending upon the rotor active power reference $p_{r a}^{*}$ at wind speed $v_{w}=6[\mathrm{~m} / \mathrm{s}]$ have been shown in figure 9 .

By analyzing the results as illustrated in Fig. 9, it is evident that by varying the rotor active power reference, the generator rotation speed can be significantly controlled. The higher the rotation speed changes, the lower the rotor active power reference, i.e. they are inversely proportional.
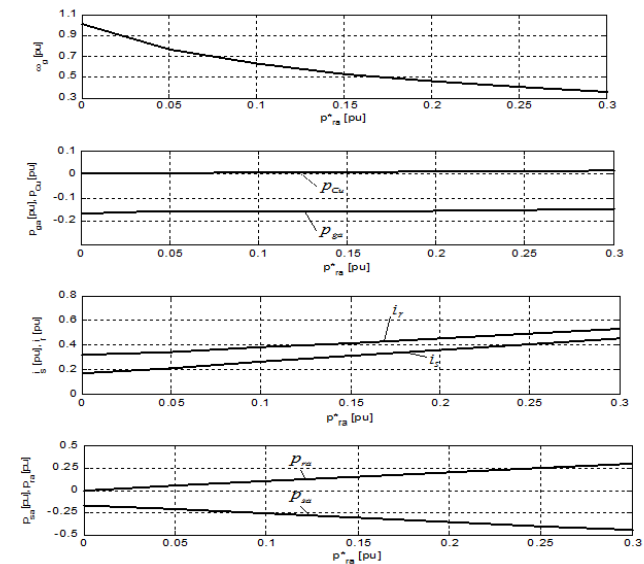

Fig. 9. DFIG stationary characteristics depending upon the rotor active power reference.

Fig. 10. shows the rotation speed responses $\omega_{g}$, respective stator $p_{s a}$ and rotor active powers $p_{r a}$, as well as stator $i_{s}$ and rotor currents $i_{r}$ respectively at sudden wind speed changes from $v_{w 1}=0.0[\mathrm{~m} / \mathrm{s}]$ to $v_{w 2}=6[\mathrm{~m} / \mathrm{s}]$ The dynamic characteristics of the response of the DFIG fitted with a rotor active power feedback to wind speed changes have been found to be stable. The response speed of generator rotation speed depends upon the inertia moments of both the wind power turbine and the DFIG.

It is necessary to conduct a detailed investigation into the interdependence of rotor active power control parameters and rotor active power reference. By selecting the correct parameters of rotor active power control the time responses with a considerably shorter transition phenomenon are obtained, while the DFIG fitted wind turbine vector control system is rendered more adaptable to sudden wind changes.
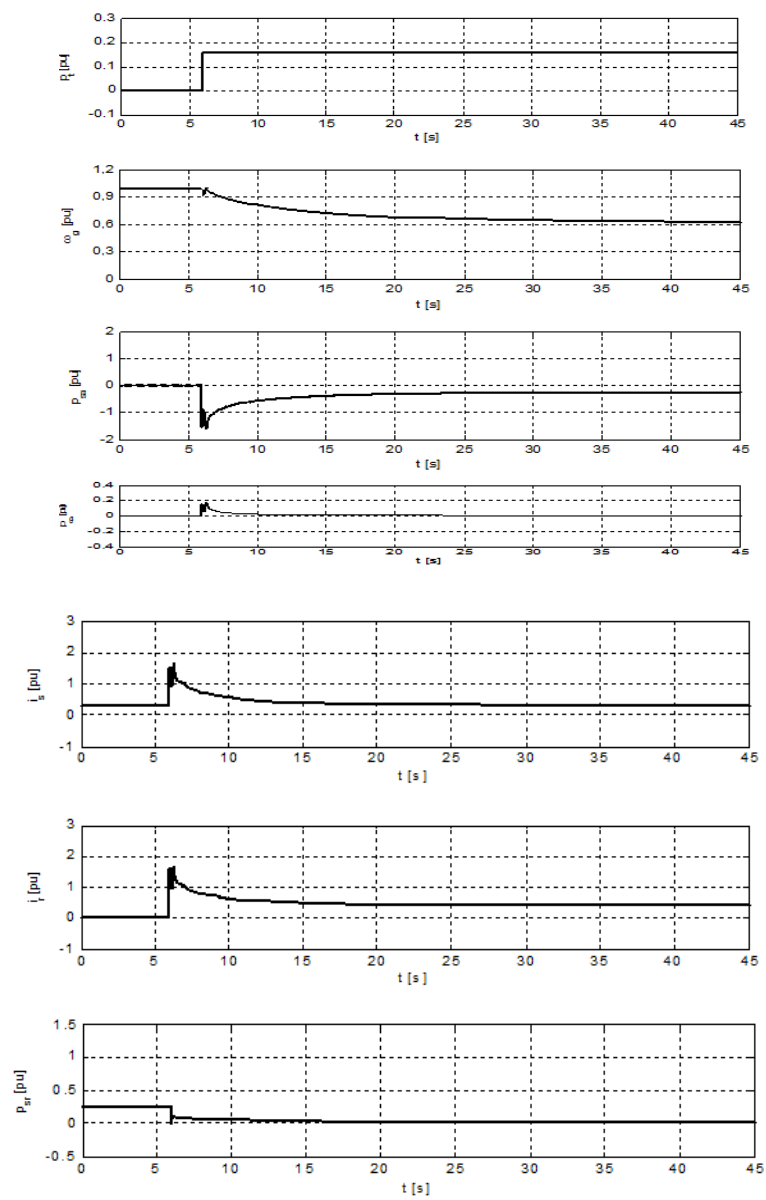

Fig. 10. Response characteristic at sudden wind speed changes; $v_{w 1}=0.0[\mathrm{~m} / \mathrm{s}], v_{w 2}=6.0[\mathrm{~m} / \mathrm{s}]$,

$$
p_{r a}^{*}=0.1[p u], K_{p r}=30.0, K_{i r}=0.015
$$

\section{CONCLUSION}

The torque- and power-droop, as two easily-achievable methods to implement droop-control in DFIG-based wind power generation units, were analyzed and compared in this paper. Small-signal analysis showed why under-speeding should be avoided and how variance of effective torquedroop could yield higher stability margins as compared to the power-droop method. Eigen-values studies 1) proved the pos- itive impact of wind-droop on system frequencystability; 2) showed that wind droop could compensate for the lack of inertia in a microgrid in the medium-frequency range; and 3) showed the positive influence of wind-droop on turbine governor and inverter droop functions. Pitchangle controller impact on wind-droop was also investigated; and it has been found that this impact is not significant. Time-domain simulations verified all analytical results and discussions; and showed that wind power generation with autonomous frequency regulation has the ability to stabilize the frequency in an isolated microgrid. Load sharing and coordination of two wind power generation in presence of real wind speed patterns and different wind-droop method 
were examined.

\section{REFERENCES}

[1] T. Bhattacharya and L. Umanand, "Negative sequence compensation within fundamental positive sequence reference frame for a stiff micro- grid generation in a wind power system using slip ring induction ma- chine," IET Elect. Power Applicat., vol. 3, no. 6, pp. 520-530, 2009.

[2] Global Wind Energy Outlook, 2010 [Online]. Available: http://www. gwec.net

[3] 20\% Wind Energy by 2030: Increasing Wind Energy's Contribution to U.S. Electricity Supply. Washington, DC, USA, Jul. 2008, U. S. Department of Energy.

[4] G. Ramtharan, J. B. Ekanayake, and N. Jenkins, "Frequency support from doubly fed induction generator wind turbines," IET Renew. Power Gen., vol. 1, pp. 3-9, 2007.

[5] J. Morren, J. Pierik, and S. W. H. de Haan, "Inertial response of vari- able speed wind turbines," Elect. Power Syst. Res., vol. 76, no. 11, pp.

980-987, Jul. 2006. 